\title{
Externally heated geothermal bridge deck: Performance analysis of the U-tube ground heat exchanger
}

\author{
Omid Habibzadeh-Bigdarvish ${ }^{1}$, Xinbao $\mathrm{Yu}^{1, *}$, and Anand J. Puppala ${ }^{2}$ \\ ${ }^{1}$ Department of Civil Engineering, the University of Texas at Arlington, TX 76019, United States \\ ${ }^{2}$ Zachry Department of Civil and Environmental Engineering, Texas A\&M University, TX 77843, United States
}

\begin{abstract}
In recent years, the geothermal heat pump de-icing system (GHDS) is introduced as a sustainable solution for bridge deck de-icing, which utilizes renewable geothermal energy. Existing GHDS designs mostly rely upon hydronic loops embedded in concrete decks. To extend the GHDS for existing bridges, a new external hydronic deck has been developed recently, which employs a hydronic pipe being attached to the bottom surface of the bridge deck. In this study, the performance of the externally heated geothermal bridge deck is investigated through winter deicing and summer recharging tests with the focus on the ground loop heat exchanger (GLHE), a key component of the GHDS. The test results show that the de-icing system was successful in maintaining the deck surface temperature above freezing in all winter tests. The soil temperature measurements indicate, the $132.5 \mathrm{~m}$ vertical U-tube ground heat exchanger is benefited from the undisturbed soil temperature of around $21^{\circ} \mathrm{C}$. The overall average hourly heat extraction of $0.67 \mathrm{~kW}$ during winter operation and average hourly heat injection of $0.69 \mathrm{~kW}$ during the summer operation were observed. Also, the ground thermal recharge test showed the increase of undisturbed soil temperature at $1.5 \mathrm{~m}$ from the geothermal borehole by $0.36^{\circ} \mathrm{C}$ after 50 days of system operation.
\end{abstract}

\section{Introduction}

Bridges are the critical infrastructures of the transportation network, which are negatively affected by the severe winter weather. Traditionally, de-icing salt and other chemical deicers are used to prevent snow and ice accumulation on the bridge deck. Application of the chemical deicers is hazardous to the environment, laborintensive, time-consuming, corrosive to the bridge deck and in some cases causes more frequent and damaging freeze/thaw cycles [1-5]. Moreover, corrosion of the bridge deck eventually leads to the repair/rehabilitation actions and work zones on the bridges, which imposes delays on the travel time of the motorists and increases the risk of an accident as well [4]. Thus, new technologies have been developed that use geothermal energy for snow/ice melting on the bridge deck surface, prevents the corrosion of the bridge deck, and minimizes the environmental footprints $[6,7]$.

Many research groups have studied different methods of application and extraction of geothermal energy in the last few decades [8-11]. In a recent application, geothermal energy has been utilized through the implementation of a geothermal heat pump de-icing system (GHDS) for snow melting and deicing bridge decks and pavements. GHDS is a ground source heat pump system (GSHP) which uses the heat output of the system for snow melting and deicing purposes. In these systems, the heat carrier fluid circulates between ground loop heat exchangers (GLHE) and the hydronic loops in contact with bridge deck/pavement and transfers heat to the bridge deck/pavement surface to melt snow and ice. The heat pump in the system helps the heat carrier fluid reach the ideal temperature appropriate for snow and ice melting. There are two types of GHDS, the conventional system which employs internal hydronic heating pipes embedded in the concrete slab of the bridge deck during the construction stage, and a newly developed system in which hydronic heating pipes are attached to the bottom surface of the bridge deck and encapsulated in a layer of insulation foam. Since the conventional system developed earlier, they have been more studied and practiced. Minsk and Lund reported previous projects of using geothermal energy for snow melting and de-icing of bridge decks [6,7], Ghasemi-Fare et al. investigated the feasibility of this system [12], and [13,14] modeled snow melting on heated pavement surfaces and validated using experimental result. Moreover, the latter type of GHDS (i.e. externally heating system) which can even be implemented for existing bridges, has been investigated in recent years by the Texas Department of Transportation (TxDOT) and studied in [15-17]. Yu et al. studied the feasibility of externally heated geothermal bridge deck and tested the system performance on a labscale bridge deck in the environmental chamber; Tests carried out on various conditions including room temperature as low as $4.4{ }^{\circ} \mathrm{C}$ [16]. The research demonstrated detailed information on externally heated geothermal bridge deck performance and presented an empirical prediction equation to estimate deck

\footnotetext{
* Corresponding author: xinbao@uta.edu
} 
temperature at given ambient and supplied heating fluid temperatures [16]. The analysis confirms that the external heating system is capable of de-icing the bridge deck with some differences with respect to the internal heating system [16]. Moreover, a comprehensive analysis of the heat transfer mechanism and energy balance of the externally heated deck was conducted using a 3D numerical model which was calibrated using the experimental results obtained in the environmental chamber [18].

Although, many researchers were investigated the overall system or bridge deck performance, however, only a few studies have been conducted on the GLHE. Balbay and Esen investigated the performance of GLHE beside the system performance in snow melting the bridge and pavement slab [19]. Their analysis includes three different geothermal borehole depths; they found the longer GLHE result in a more efficient system with a coefficient of performance (COP) values of 1.99, 2.66 and 3.05 for different borehole depths of $30 \mathrm{~m}, 60 \mathrm{~m}$ and $90 \mathrm{~m}$ respectively [19]. Moreover, there are some exemplary studies that investigated the performance of the GLHE, however, not in the geothermal snow melting or deicing system. Tang and Nowamooz investigated the factors affecting the performance of the ground heat exchanger on the $20 \mathrm{~m}$ U-Tube heat exchanger using a $3 \mathrm{D}$ finite element numerical simulation model [20]. They found that shallow borehole heat exchanger tends to have a higher efficiency of $8 \%$ when installed in the sand than in clay [20]. Same authors demonstrated that higher performance of borehole heat exchanger was observed in warmer climate, less vegetated field, higher groundwater velocity; higher grout thermal conductivity, larger grout diameter, larger shank spacing, more additional U-pipes, larger U-pipe inner diameter, thinner U-pipe, higher Upipe thermal conductivity, more stable heat load, and lower heat load level [20]. [21] also studied the impact of geological parameters and found geothermal gradient, rock thermal conductivity, and heat capacity of rock-soil are in order the three main geological parameters on the thermal extraction load of a medium-deep borehole heat exchanger. Moreover, Kerme and Fung's analysis highlighted that the heat transfer into the borehole varies along with the borehole depth due to the variation of parameters such as fluid temperature, grout, borehole wall, and ground temperature along the axial direction [22].

However, to study the feasibility and performance of the proposed hydronic systems it is required to experiment with a full-scale system of the externally heated geothermal bridge deck in real winter events. Moreover, it is essential to study the energy performance of the GLHEs as the key component of the GHDS, which has a huge impact on the overall system performance. In this study, the performance of the Utube ground heat exchanger of the externally heated geothermal bridge deck is discussed and the summary of the thermal response and heating performance of the full-scale mock-up of the externally heated geothermal bridge deck is highlighted.

\section{De-icing system}

\subsection{Overview}

A mock-up bridge has constructed and a geothermal heat pump de-icing system (GHDS) has utilized to de-ice the snow/ice on the bridge deck surface. Figure 1 illustrates the schematic diagram of the mock-up geothermal bridge. The dimensions of the whole bridge slabs are $4.87 \mathrm{~m} \times 10.97 \mathrm{~m}$ including 12 standard PCP panels. The mock-up bridge deck consists of three zones: an external heating zone, an internal heating zone, and a control zone. It utilizes both the traditional type of GHDS which uses internal hydronic pipe embedded in the concrete slab and newly developed method which utilizes external hydronic pipe, attached to the bottom surface of the bridge deck and covered by a layer of insulation foam. The end section of the bridge deck is also considered as a control area with no heating.

\subsection{Test site}

The mock-up of the externally heated bridge deck is constructed during February and March of 2018 in Dallas-Fort Worth metroplex, Texas, USA. Figure 2 shows the weather information of the region from the nearest weather station to the test site (i.e., DFW international airport). The region has the annual high and low temperatures of $25^{\circ} \mathrm{C}$ and $14^{\circ} \mathrm{C}$ respectively. January is typically regarded as the coldest month, recorded an average low of $2.9^{\circ} \mathrm{C}$. The average annual rainfall precipitation is $95.3 \mathrm{~cm}$ for the average 81 days with precipitation per year. Most of the annual precipitation is due to thunderstorm activity, which occurs most frequently in the spring and classified by occasional heavy rainfall over short periods. Moreover, on average, the region has experienced $5 \mathrm{~cm}$ of annual snowfall. Although the region is familiar with mild winters, several snowstorms in recent years are experienced such as the snowstorm on March 4-5, 2015, which was the fourth-largest ever recorded in a 24-hour period during March in the region. Over two days, 8.89 $\mathrm{cm}$ of snowfall and the average ambient temperature during snowfall was recorded around $-2.2^{\circ} \mathrm{C}$.

Moreover, the subsurface investigation was carried out using the boring logs of a nearby bridge. It showed the site consists of relatively uniform soil layers, the top $12.2 \mathrm{~m}$ covered by sandy clay with alternating sand/gravel seams which follows by a limestone layer. The boring $\operatorname{logs}$ stop at $18.3 \mathrm{~m}$. Based on the local knowledge of the region, it is estimated that limestone is extended up to a depth that is of interest to the study. Groundwater table was encountered at $4.6 \mathrm{~m}$ below ground surface at the time of drilling. Figure 3 illustrates the ground temperature profile recorded by an on-site temperature monitoring borehole. 


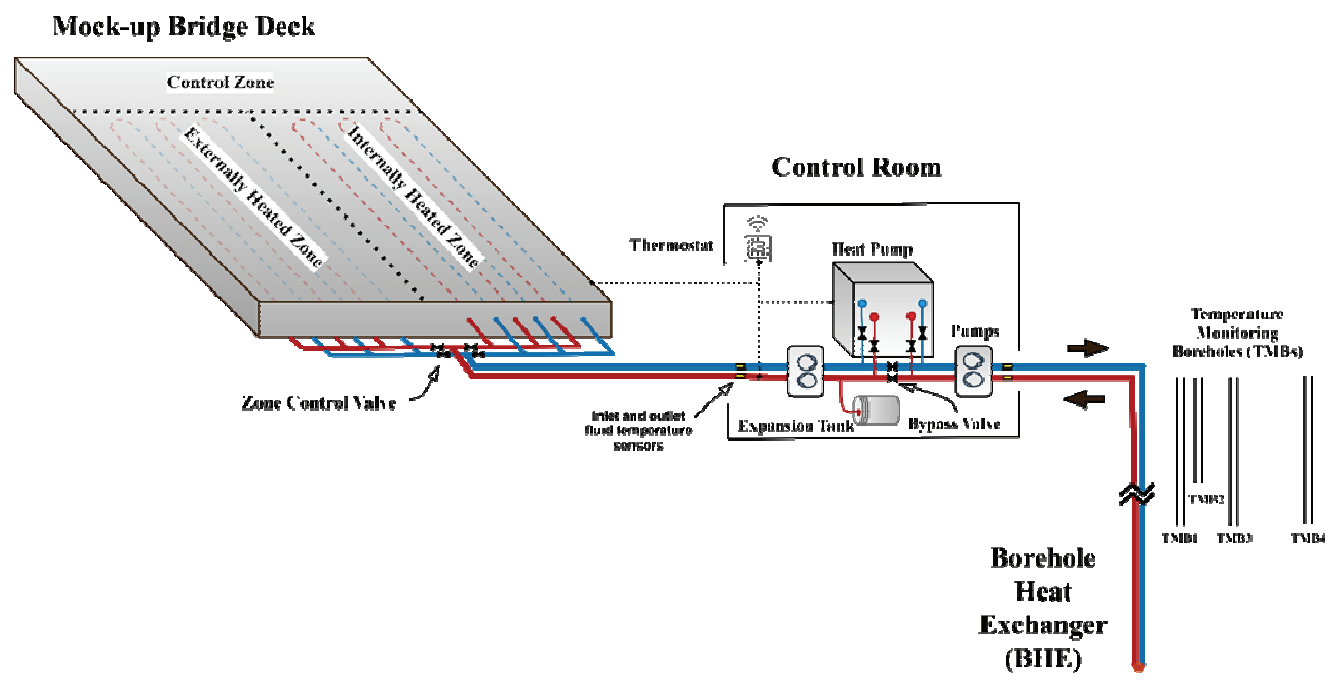

Fig. 1. Conceptual diagram of the mock-up geothermal bridge.

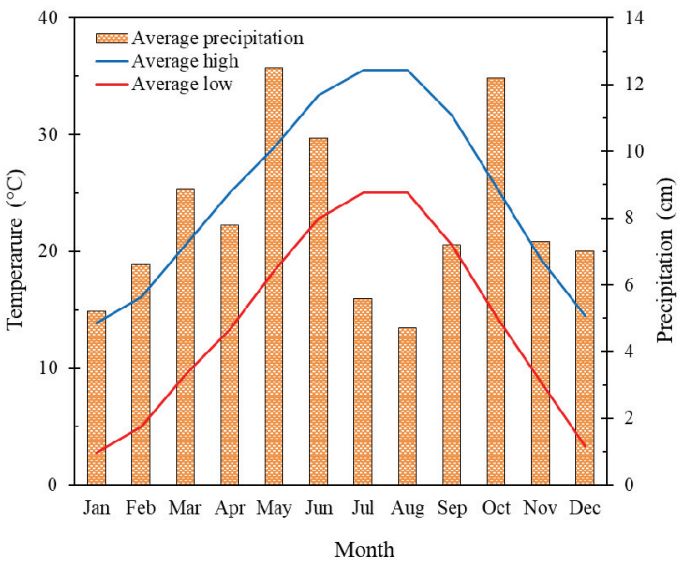

Fig. 2. Test site weather information (Source: [23]).

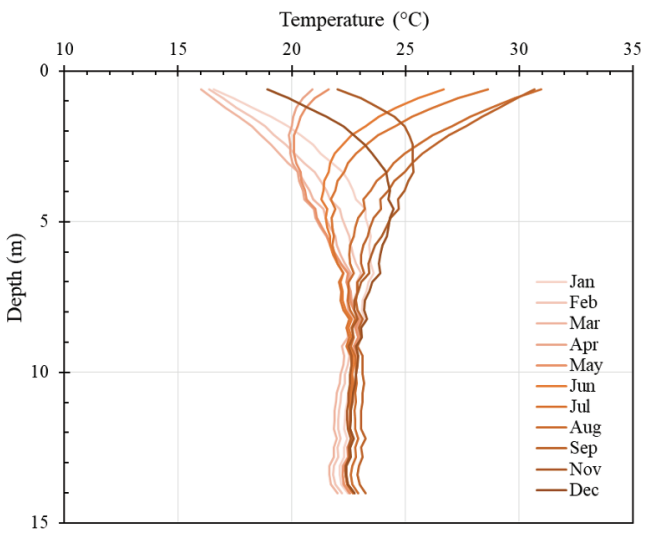

Fig. 3. Test site ground temperature profile.

The result represents the average monthly ground temperature up to $14 \mathrm{~m}$ below the surface. Moreover, formation thermal response test was carried out on-site by a contractor and the result shows that the formation has the thermal conductivity of $1.99 \mathrm{~W} / \mathrm{m} . \mathrm{K}$ and thermal diffusivity of $0.078 \mathrm{~m}^{2} /$ day. The undisturbed temperature of the soil was found to be about $21.4^{\circ} \mathrm{C}$.

\subsection{Thermal response of the bridge deck}

Winter climatic conditions were closely monitored from November of 2018 to March 2019. The geothermal system was operated when a cold front below freezing temperature was forecasted. The de-icing system was operated in several modes depending on the operational condition of the geothermal heat pump and the heated deck. The geothermal heat pump was allowed to be switched off when the winter event was mild (i.e. minimum ambient temperature greater than $-2.8^{\circ} \mathrm{C}$ ), and the heat demand was less. Two heated zones, i.e., the internally heated zone and externally heated zone, were operated independently by a control valve. All winter tests focused on testing the heating performance of the externally heated zone, the focus of this research. Therefore, most of the tests were operated with the external heating zone turned on only by closing the control valve of the internally heated zone. In all the tests, the goal was to melt the ice on the bridge deck surface. In addition, a by-pass was provided so that the system could operate in two modes: full-load and bypass. In the full-load operation mode, the control valves of the heat pump are closed and the flow goes through the heat pump. In the full load operation mode, the geothermal heat pump is active; while in bypass mode, the geothermal heat pump is off, and the heat carrier fluid circulates directly through the bypass. Table 5 summarizes the seven winter tests performed in the 2018-2019 winter. The number of freezing hours were determined from the air temperature measured by the thermocouple installed at the bridge site. The number of freezing hours, minimum air temperature, and average air temperature during the freezing period are obtained to characterize the winter events.

The minimum surface temperature during the freezing period was obtained from the sensor node in the middle of the heated zone and embedded in the concrete, approximately $2.5 \mathrm{~cm}$ below the deck surface. This sensor was selected as a representative for temperature response of the bridge deck during the coldest period of the winter test. Figure 4 shows, during all events, the 
system was capable of keeping the heated surface temperature above freezing.

Table 1. Summary of tests and weather conditions.

\begin{tabular}{|c|c|c|c|c|c|}
\hline \multirow[b]{2}{*}{ Test } & \multirow{2}{*}{$\begin{array}{c}\text { Duration } \\
\text { (hr.) }\end{array}$} & \multicolumn{3}{|c|}{ Freezing ambient temperature } & \multirow[b]{2}{*}{ Mode } \\
\hline & & $\begin{array}{c}\text { Duration } \\
\text { (hr.) }\end{array}$ & Ave. $\left({ }^{\circ} \mathrm{C}\right)$ & Min. $\left({ }^{\circ} \mathrm{C}\right)$ & \\
\hline$\# 1$ & 71 & 9.0 & -1.3 & -2.2 & Bypass \\
\hline$\# 2$ & 76 & 5.4 & -0.3 & -0.8 & Full load \\
\hline \#3 & 77 & 9.8 & -2.4 & -5.3 & Full load \\
\hline$\# 4$ & 122 & 14.9 & -1.7 & -4.2 & Full load \\
\hline$\# 5$ & 72 & 11.7 & -2.4 & -4.3 & Full load \\
\hline$\# 6$ & 343 & 12.4 & -0.7 & -1.4 & Bypass \\
\hline$\# 7$ & 55 & 36.1 & -3.5 & -6.2 & Full load \\
\hline
\end{tabular}

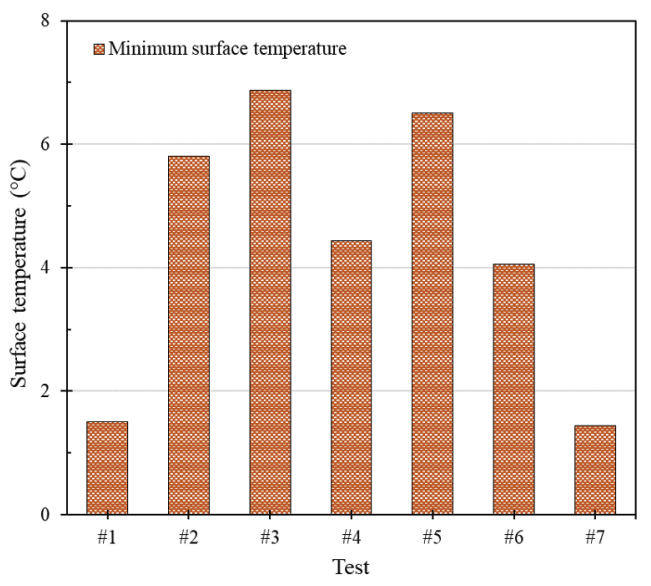

Fig. 4. The minimum surface temperature during winter tests.

\subsection{Performance of the GLHE}

\subsubsection{Overview}

This study involves one geothermal borehole of $132.5 \mathrm{~m}$ (from ground level) deep and $14 \mathrm{~cm}$ diameter which hosted a single U-tube heat exchanger loops made of high-density polyethylene (HDPE) pipe with $3.45 \mathrm{~cm}$ inside diameter, and five temperature monitoring boreholes (TMBs), which equipped with thermistor strings and radially scattered around the geothermal borehole to investigate the temperature distribution in the soil and at different depths. Table 2 shows the detail of the TMBs.

Table 2. Details of temperature monitoring boreholes (TMBs).

\begin{tabular}{|c|c|c|}
\hline Borehole & Length $(\mathrm{m})$ & Distance from GLHE $(\mathrm{m})$ \\
\hline TMB1 & 18.3 & 0.5 \\
\hline TMB2 & 13.7 & 0.6 \\
\hline TMB3 & 18.3 & 0.9 \\
\hline TMB4 & 18.3 & 1.5 \\
\hline Far-Field & 18.3 & 7.6 \\
\hline
\end{tabular}

The efficiency of the geothermal system mostly depends on the ground loop heat exchangers (GLHE). One of the key parameters significantly affecting the design of the geothermal system is the outlet water temperature of the geothermal borehole. This section discusses the GLHE performance at two different modes, namely: heating, and cooling.

\subsubsection{Winter operation}

During the cold winter weather, the system is operating under heating mode in which the de-icing system tries to draw heat from the ground and utilize it to de-ice the bridge deck surface. In this study, the extracted heat can be directly transferred to the bridge deck through bypass or transferred to the evaporator of the heat pump when the system is working in the full-load mode. Table 3 shows the average fluid temperature at the inlet $\left(\mathrm{T}_{\text {in }}\right)$ and outlet $\left(\mathrm{T}_{\text {out }}\right)$ of the GLHE for different tests. As the performance of the GLHE is highly depends on the weather condition, it can be observed the maximum inlet and outlet temperature difference $(\Delta \mathrm{T})$ occurred during coldest winter events, test \#5 and \#7.

Table 3. Summary of the inlet and outlet during the tests.

\begin{tabular}{|c|c|c|c|}
\hline Test & Ave. $\mathrm{T}_{\text {in }}\left({ }^{\circ} \mathrm{C}\right)$ & Ave. $\mathrm{T}_{\text {out }}\left({ }^{\circ} \mathrm{C}\right)$ & $\Delta \mathrm{T}\left({ }^{\circ} \mathrm{C}\right)$ \\
\hline$\# 1$ & n/a & n/a & n/a \\
\hline$\# 2$ & n/a & n/a & n/a \\
\hline$\# 3$ & 17.19 & 17.47 & 0.27 \\
\hline$\# 4$ & 17.58 & 16.83 & 0.26 \\
\hline$\# 5$ & 16.14 & 16.59 & 0.45 \\
\hline$\# 6$ & 14.41 & 17.64 & 0.26 \\
\hline$\# 7$ & 15.18 & 15.63 & 0.44 \\
\hline
\end{tabular}

The heat extraction from GLHE can be calculated as follow:

$$
\dot{Q}_{c}=\dot{m} C_{p}\left(T_{\text {out }}-T_{\text {in }}\right)
$$

Where $\dot{m}, C_{p}, T_{\text {out }}$ and $T_{\text {in }}$ are mass flow rate, the specific heat of the fluid, outlet, and inlet fluid temperatures of GLHE, respectively.

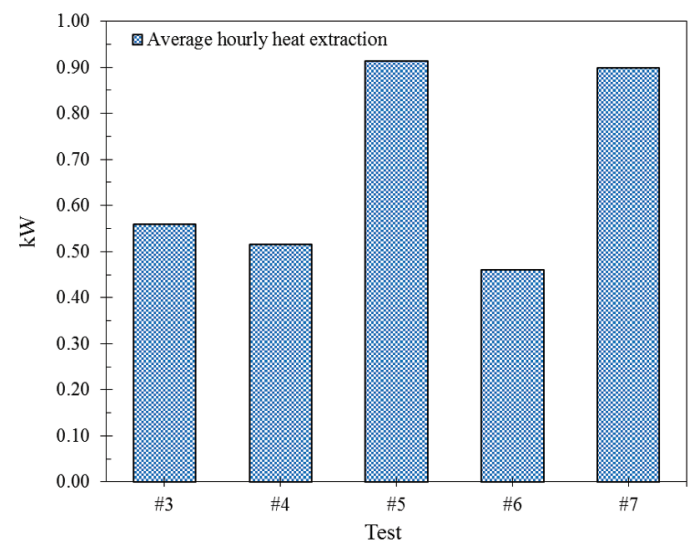

Fig. 5. Average hourly heat extraction for each test.

Figure 5 shows the average hourly heat extraction during each winter test. As expected, test \#5 and \#7 had a higher extraction rate due to the higher inlet and outlet temperature difference. Overall, the GLHE had an average hourly heat extraction of $0.67 \mathrm{~kW}$. Also, with regards to the unit length of the GLHE, it had the 
average energy extraction rate of $5.05 \mathrm{~W} / \mathrm{m}$. It should be mentioned, unfortunately, the string sensors of the underground loops and temperature monitoring boreholes (TMBs) were malfunctioned during the winter operation of 2018-2019 and the data could not be utilized for this period.

\subsubsection{Summer operation}

During summer 2019, the GHDS was tested in cooling mode and the system was operated through the bypass in which heat carrier fluid transferred the heat from bridge deck to the ground. However, the purpose of this test was to investigate the ground thermal recharge. Figures 6 and 7 illustrate the ambient temperature and inlet/outlet fluid temperature variation during this test, respectively.



Fig. 6. Ambient temperature variation during the summer test.

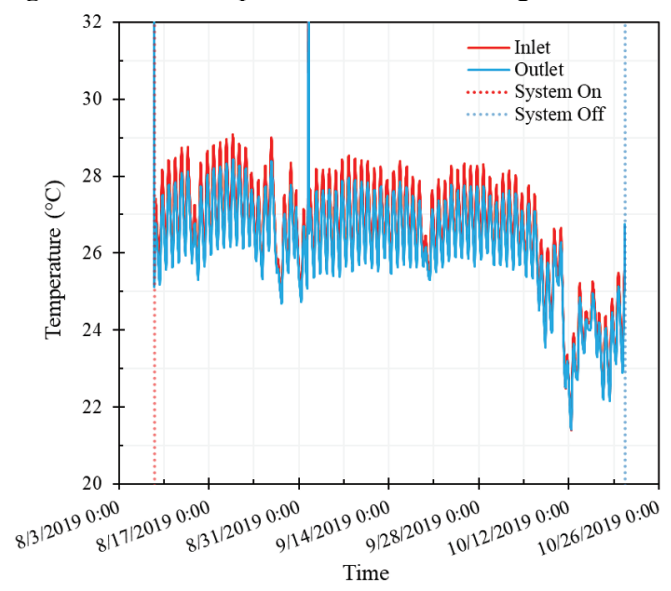

Fig. 7. Borehole Inlet/outlet temperature variation during the summer test.

Table 4. Summary of ground thermal recharge test.

\begin{tabular}{|c|c|}
\hline Test & Ground thermal recharge \\
\hline Duration & 73.25 days \\
\hline Average $\mathrm{T}_{\text {in }}$ & $26.50^{\circ} \mathrm{C}$ \\
\hline Average $\mathrm{T}_{\text {out }}$ & $26.16^{\circ} \mathrm{C}$ \\
\hline Average $\Delta \mathrm{T}$ & $0.34^{\circ} \mathrm{C}$ \\
\hline Ave. hourly heat injection & $0.69 \mathrm{~kW}$ \\
\hline Ave. heat injection per unit length & $5.17 \mathrm{~W} / \mathrm{m}$ \\
\hline
\end{tabular}

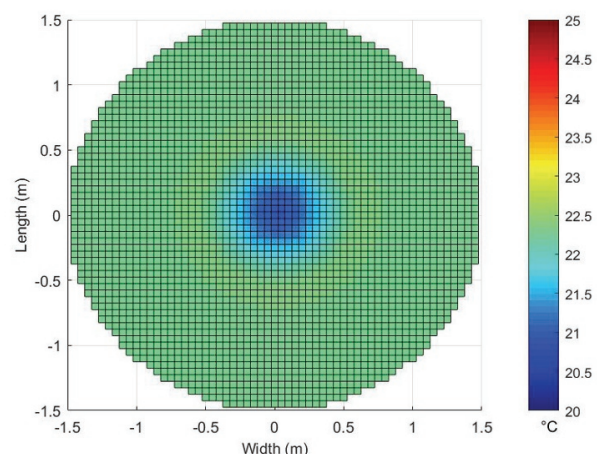

(a)

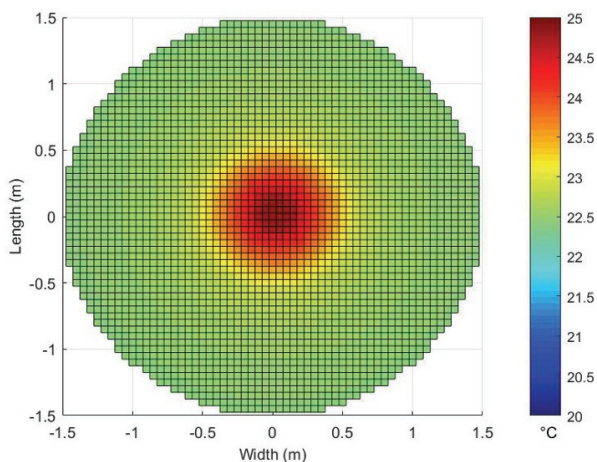

(b)



(c)

Fig. 8. Temperature distribution of GLHE surrounding soil at $13.7 \mathrm{~m}$ below the ground surface: (a) Before system onset, (b) 15 days after system onset, (c) 50 days after system onset.

Table 4 shows a summary of the ground thermal recharge test. The result expresses the temperature differences of $0.34{ }^{\circ} \mathrm{C}$ between the inlet and outlet fluid of GLHE. Equation 1 has used to calculate the energy transferred to the soil. The heat was injected to the ground with an average hourly rate of $0.69 \mathrm{~kW}$. Also, the result showed an average heat injection per unit length of $5.17 \mathrm{~W} / \mathrm{m}$. In addition, it demonstrates the average heat injection rate in summer was slightly higher than the average heat extraction rate in winter. The soil temperature at different depth and distance from geothermal borehole were monitored by the TMBs. Figure 8 illustrates the radial temperature distribution around GLHE at $13.7 \mathrm{~m}$ below the surface and at different times of the ground thermal recharge test. The radial temperature distribution plots were generated 
using MATLAB software employing the cubic interpolation method for scattered data collected from TMBs. Also, it is assumed that the temperature distribution is uniform in each direction around the GLHE. It can be observed how the temperature in the soil has changed following the circulation of hot fluid in the GLHE during the tests. The result states, the temperature in the soil at $0.6 \mathrm{~m}, 0.9 \mathrm{~m}$, and $1.5 \mathrm{~m}$ from geothermal borehole has increases by $0.82{ }^{\circ} \mathrm{C}, 0.6{ }^{\circ} \mathrm{C}$, and $0.36^{\circ} \mathrm{C}$ after 50 days of system operation.

\section{Conclusions}

This study discusses the performance of the U-tube ground heat exchanger of the externally heated geothermal bridge deck. It also highlights the summary of the thermal response and heating performance of the bridge deck in the winter events. The key findings of this research are summarized as follows:

- The externally heated geothermal bridge deck is practiced on the $4.87 \mathrm{~m} \times 10.97 \mathrm{~m}$ mock-up bridge. The geothermal de-icing system was successful in maintaining the surface temperature of the externally heated zone above freezing. The result showed the minimum surface temperature of 1.44 ${ }^{\circ} \mathrm{C}$ during the minimum ambient temperature of $6.2^{\circ} \mathrm{C}$.

- The $132.58 \mathrm{~m}$ (from ground level) deep GLHE had the overall average hourly heat extraction of 0.67 $\mathrm{kW}$ during winter operation and average hourly heat injection of $0.69 \mathrm{~kW}$ during the summer operation.

- The ground thermal recharge test increased the undisturbed soil temperature at $0.6 \mathrm{~m}, 0.9 \mathrm{~m}$, and $1.5 \mathrm{~m}$ from geothermal borehole by $0.82{ }^{\circ} \mathrm{C}, 0.6^{\circ} \mathrm{C}$, and $0.36^{\circ} \mathrm{C}$ after 50 days of system operation.

The authors appreciate the financial support provided for this study from the Texas Department of Transportation (TxDOT). The help of the research supervisor, Sonya Badgley; James Kuhr; and TxDOT engineers, Richard Williammee and Justin Thomey, is also acknowledged. Special thanks to the Fort Worth maintenance group and Tom Weatherspoon for help with the machinery. The authors are also thankful to Howard Newton of Image Engineering Group, Ltd.; William McPike of the Geothermal Drilling, Inc.; and Pile Dynamics, Inc. The authors thank Mark Hurley, Sunil Adhikari, Rahul Yadav, Hiramani Raj Chimauriya, and Samrat Raut for assistance with the construction of the mock-up bridge.

\section{References}

1. R. Baboian, "Synergistic Effects of Acid Deposition and Road Salts on Corrosion," in Corrosion Forms and Control for Infrastructure, V. Chaker, ed. (ASTM International, 1992), pp. 17-29.

2. M. Yunovich, N. Thompson, and Y. P. Virmani, "Life cycle cost analysis for reinforced concrete bridge decks," in CORROSION 2003 (NACE International, 2003).

3. M. Fischel, Evaluation of Selected Deicers Based on a Review of the Literature. The SeaCrest Group. Louisville, CO (Report Number CDOT-DTD, 2001).
4. O. Habibzadeh-Bigdarvish, X. Yu, G. Lei, T. Li, and A. J. Puppala, "Life-Cycle cost-benefit analysis of Bridge deck de-icing using geothermal heat pump system: A case study of North Texas," Sustain. Cities Soc. 47, 101492 (2019).

5. M. Mahedi, S. Satvati, B. Cetin, and J. L. Daniels, "Chemically Induced Water Repellency and the Freeze-Thaw Durability of Soils," J. Cold Reg. Eng. 34(3), 4020017 (2020).

6. L. D. Minsk, Heated Bridge Technology-Report on ISTEA Sec. 6005 Program (United States. Federal Highway Administration, 1999).

7. J. W. Lund, "Reconstruction of a pavement geothermal deicing system," Geo-Heat Cent. (1999).

8. A. Binod, S. Kenichi, J. Peter, and L. Laloui, "Thermo-mechanical behaviour of energy piles," Geotechnique-London- 62(ARTICLE), 503-519 (2012).

9. G. Zhang, C. Xia, M. Sun, Y. Zou, and S. Xiao, "A new model and analytical solution for the heat conduction of tunnel lining ground heat exchangers," Cold Reg. Sci. Technol. 88, 59-66 (2013).

10. Y. Nam and H.-B. Chae, "Numerical simulation for the optimum design of ground source heat pump system using building foundation as horizontal heat exchanger," Energy 73, 933-942 (2014).

11. D. Sterpi, A. Angelotti, O. Habibzadeh Bigdarvish, and D. Jalili, "Heat transfer process in a thermoactive diaphragm wall from monitoring data and numerical modelling," in 9th European Conference on Numerical Methods in Geotechnical Engineering (Taylor and Francis Group, 2018), 1, pp. 731-736.

12. O. Ghasemi-Fare, G. A. Bowers, C. A. Kramer, T. Y. Ozudogru, P. Basu, C. G. Olgun, T. Bulbul, and M. Sutman, A Feasibility Study of Bridge Deck Deicing Using Geothermal Energy (Mid-Atlantic Universities Transportation Center, 2015).

13. X. Liu, S. J. Rees, and J. D. Spitler, "Modeling snow melting on heated pavement surfaces. Part I: Model development," Appl. Therm. Eng. 27(5-6), 11151124 (2007).

14. X. Liu, S. J. Rees, and J. D. Spitler, "Modeling snow melting on heated pavement surfaces. Part II: Experimental validation," Appl. Therm. Eng. 27(56), 1125-1131 (2007).

15. X. Yu, A. J. Puppala, and N. Zhang, Use of Geothermal Energy for Deicing Approach Pavement Slabs and Bridge Decks, Phase 1 (Texas. Dept. of Transportation. Research and Technology Implementation Office, 2017).

16. X. Yu, M. T. Hurley, T. Li, G. Lei, A. Pedarla, and A. J. Puppala, "Experimental Feasibility Study of A New Attached Hydronic Loop Design for Geothermal Heating of Bridge Decks," Appl. Therm. Eng. 114507 (2019).

17. T. Li, G. Lei, X. Yu, N. Zhang, and A. J. Puppala, "Numerical feasibility study of an externally heated geothermal bridge deck," in IFCEE 2018 (2018), pp. 758-767.

18. T. Li, X. Yu, G. Lei, O. Habibzadeh-Bigdarvish, and M. Hurley, "Numerical Analyses of a 
Laboratory Test of a Geothermal Bridge Deck Externally Heated Under Controlled Temperature," Appl. Therm. Eng. 115255 (2020).

19. A. Balbay and M. Esen, "Experimental investigation of using ground source heat pump system for snow melting on pavements and bridge decks," Sci. Res. Essays 5(24), 3955-3966 (2010).

20. F. Tang and H. Nowamooz, "Factors influencing the performance of shallow Borehole Heat Exchanger," Energy Convers. Manag. 181, 571-583 (2019).

21. J. Liu, F. Wang, W. Cai, Z. Wang, and C. Li, "Numerical investigation on the effects of geological parameters and layered subsurface on the thermal performance of medium-deep borehole heat exchanger," Renew. Energy 149, 384-399 (2020).

22. E. D. Kerme and A. S. Fung, "Heat transfer simulation, analysis and performance study of single U-tube borehole heat exchanger," Renew. energy 145, 1430-1448 (2020)

23. Climate data of DFW international airport, Texas, U.S. (2019). https://www.usclimatedata.com/climate/dallas-dfwintl-arpt/texas/united-states/ustx0328/2018/2. 